\title{
RAZONES PARA UN CANON HISPÁNICO
}

\author{
José María POZUELO YVANCOS \\ Universidad de Murcia \\ pozuelo@um.es
}

Resumen: En un contexto de ruptura del consenso académico a raíz de los debates en torno al canon y a los cultural studies, en este artículo se abordan algunos de los factores que otorgan unidad a la cultura literaria hispánica y permiten hablar de la fuerza de un canon hispánico supranacional.

Abstract: In a context of rupture of the academical consensus as a result of the debate about literary canon and cultural studies, this article tackles some of the factors that grant unity to the Hispanic literary culture and allow talking about the force of a Hispanic canon with a supranational nature.

Palabras clave: Canon. Hispanismo. Cultura. Literatura.

Key Words: Canon. Hispanism. Culture. Literature. 


\section{LA UNIDAD DE UNA CULTURA LITERARIA}

La cuestión del canon siempre ha sido controvertida. Resuenan todavía las muchas reacciones contrarias a la publicación del famoso libro de Harold Bloom, El canon Occidental. En la primera parte del libro publicado con Rosa María Aradra Teoría del canon y literatura española (2000) he planteado que la virulencia de los debates entre las posiciones que sobre la idea de canon sostienen Harold Bloom, George Steiner, Stanley Fish y otros, frente a los llamados cultural studies, están evidenciando la fuerte ruptura de un consenso académico respecto a los programas de estudios, los curricula, y el corpus de obras literarias sobre las que debe asentarse.

Esa ruptura tiene en la tradición norteamericana contextos particulares de enfrentamiento entre miembros de diferentes tradiciones científicas, pero también de lucha de poder institucional con un trasfondo político evidente, en que nuevas «identidades» culturales, dotadas de nuevos instrumentos de análisis, que durante mucho tiempo han estado en la periferia, han venido a disputar y discutir no sólo el corpus de textos sobre los que asentaban los estudios literarios, sino, por esa contigüidad fundamental a la que antes me referí, también el sistema teórico o centro de administración del canon del que se deduce aquel conjunto o corpus de textos.

Sin embargo, una peculiaridad muy definida de la literatura escrita en español, ya sea en América o en España, es el sentimiento extendido entre los escritores de ambos lados de pertenecer a un tronco común de experiencias literarias, compartido por los millones de lectores que les siguen, que no están muy interesados ni preocupados por la identidad nacional de cada uno de los que escriben en español. Estudiar ese sentimiento de unidad de la literatura y las razones de que se haya formado como tal, nos llevaría a varias realidades convergentes y sería mayor empeño del que puedo permitirme. Plantearé aquí solamente de seis factores entre otros varios que proporcionan a la literatura escrita en español una particular unidad.

El primer factor de unidad fundamental ha sido el Quijote de Cervantes, que es sentido en las tierras de América como lo que es: una obra suya. Pero no sólo y no principalmente porque las tierras americanas y españolas fueran un sólo Estado en el siglo XVII. Ese hecho no es el predominante para el sentimiento de pertenencia y filiación. Es más, podría ser al contrario, en una época en que los movimientos de poscolonialismo han arrumbado las identidades antiguas fundamentadas en sentido primordialmente político. El enorme ensayista que fue Edward Said hablaba de que, en cultura, más im- 
portante que una filiación es una afiliación, es decir, la manera como alguien se apropia para sí de lo quiere suyo, y que desde entonces ciertamente lo es. El Quijote, lo decía Carlos Fuentes, fundó un «territorio de la Mancha» que tiene todas las dimensiones y extensión de quienes hablan una misma lengua, se encuentren donde se encuentren.

Hay un hermoso cuento de Manuel Mújica Láinez, incluido en su libro Misteriosa Buenos Aires en que ha hablado de esa afiliación al modo sutil y rico en que la literatura sabe hacerlo. El cuento al que me refiero se titula «El libro (1605)» y narra la manera como un lector americano se encuentra, en un cofre enviado desde España, con un primer ejemplar del Quijote, y comienza a leerlo, emocionado hasta las lágrimas.

Y precisamente el nombre de Cervantes ha sido protagonista de otros dos factores recientes que han contribuido como muy pocos al sentimiento de unidad de la literatura escrita en América y España: me refiero a los Premios Cervantes y la creación misma del Instituto Cervantes.

Si recorremos la lista de escritores laureados con el Premio Cervantes, instituido en 1976, encontraremos que el primer premiado fue el poeta Jorge Guillén y el segundo el novelista Alejo Carpentier, en 1977. Desde 1979 en que se dio conjuntamente a Gerardo Diego y a Jorge Luis Borges se tomó la decisión de alternar en lo sucesivo, en una ley no escrita, pero justamente seguida casi siempre, a un escritor español y uno americano. De tal forma que, recorriendo solamente a los que lo han recibido principalmente como prositas, tenemos que desde 1980 lo han recibido: Onetti, Sábato, Torrente Ballester, Carlos Fuentes, María Zambrano, Augusto Roa Bastos, Adolfo Bioy Casares, Francisco Ayala, Miguel Delibes, Vargas Llosa, Camilo José Cela, Guillermo Cabrera Infante, Jorge Edwards, Francisco Umbral, Álvaro Mutis, José Jiménez Lozano, Rafael Sánchez Ferlosio, Sergio Pitol y Antonio Gamoneda.

El otro factor de unidad es el de los centros que con el nombre de Instituto Cervantes hay distribuidos por todo el mundo de habla no hispana, y en cuyas clases y lecturas se recorren escritores tanto españoles como americanos, en una tradición común, convergente con el factor del Hispanismo como realidad universitaria, donde asimismo en los Departamentos de español, o estudios Hispánicos (así se llaman muchas veces) se reúnen escritores de las dos orillas del Atlántico. La iniciativa del Instituto Cervantes, de nombrar la Biblioteca de cada centro con el nombre de un escritor laureado con ese Premio, ha dado emblemática sanción a ese factor de unidad, que lo 
es primero como contundente principio en los anaqueles mismos de cada $\mathrm{Bi}$ blioteca, y lo ha sido antes en la experiencia de los usuarios, lectores de literatura escrita en español.

Un tercer factor de unidad cultural literaria ha sido la profunda influencia que en tiempos posteriores al Quijote se ha dado entre la literatura escrita. De la misma forma que el Periquillo Sarniento de Fernández Lizardi no podría entenderse sin la picaresca desde el Lazarillo a Quevedo, la poesía española de la modernidad del Xx está cohesionada en torno a la figura de Rubén Darío. Igualmente ocurre del lado de los estudios. Uno de los estudios pioneros en la recuperación de Góngora fue el que dedicó el mexicano Alfonso Reyes al Polifemo, estudio que influiría mucho junto con los de Dámaso Alonso por aquellas fechas del 27. Y del otro lado el estudio emblemático del catedrático español Amado Alonso sobre Poesía y estilo de Pablo Neruda es un referente ineludible, como lo es el del propio don Amado sobre La gloria de don Ramiro de Emilio Larreta, el de Pedro Salinas sobre Rubén Darío, el de Octavio Paz sobre Luis Cernuda, incluido en Los signos en rotación, o los de María Rosa Lida sobre La Celestina y tantos otros que podrían convocarse.

Tenemos por tanto que el ensayismo americano ha dedicado a la literatura española (y dejo sin decir nada ahora del factor del cervantismo) tantos estudios como se han producido de españoles para con la literatura americana. Y ello, porque como dice Octavio Paz: «No hay una literatura peruana, argentina o cubana: tampoco hay una literatura española: al menos desde el siglo XVI [...] No se clasifica a los escritores por su nacionalidad o su nacimiento, sino por su lenguaje» (O. Paz, 1991: 15). Y ese lenguaje es estudiado como propio por todos ellos.

El cuarto factor de unidad ha sido los múltiples intercambios, a menudo forzados por los exilios, tanto de españoles en América como de los escritores americanos en España. Bien sea como exilios políticos, bien como exilios culturales, de hecho ha habido una impronta decisiva de ambos, mutuamente beneficiados del factor de transducción. Aunque fundamentados primero en su actividad diplomática, ha sido un hecho que sin Rubén Darío o sin Pablo Neruda la poesía española de comienzos del siglo XX sería de otra manera. También Borges o el propio Alfonso Reyes tuvieron decisivas estadías en España. Pero en el siglo Xx fue la guerra civil española la que de manera obligada llevó a españoles a América. La acogida que en tierras de Argentina y México, Puerto Rico o Cuba, tuvieron intelectuales, profesores y creadores republicanos resultó decisiva en dos maneras. Sirvió como fundamento de cohesión y pertenencia a una misma cultura. Juan Ramón Jiménez, 
Max Aub, Luis Cernuda, Francisco Ayala, Juan Chabás enseñaron en América, y en el caso de México y Argentina sirvieron como dinamizadores de su vida cultural. Testigos de ambos fenómenos permanecen el denominado Colegio de México y el Instituto Amado Alonso de Buenos Aires; ambos centros han sido cuna fundamental del Hispanismo internacional, proyectado luego a Estados Unidos.

De igual forma la realidad política americana o bien las escasas posibilidades de desarrollo en regímenes hostiles a la cultura, trajo a España como exiliados durante la segunda mitad del Xx, a escritores como Juan Carlos Onetti, Cortázar, Roa Bastos, Vargas Llosa, Cabrera Infante, Jorge Edwards, etc., que revolucionaron asimismo la narrativa escrita en España.

Vengo con lo dicho sobre la realidad del Hispanismo, al quinto factor de unidad. La creación de la Asociación Internacional de Hispanistas que desde hace cincuenta años reúne a miles de profesores de lengua y literatura en español en centros universitarios de todos los países del mundo. Esta realidad fue decisiva por ejemplo en Estados Unidos, donde el Hispanismo fue refugio de muchos de los principales exilados republicanos como Américo Castro, Casalduero, Vicente Llorens, Pedro Salinas o Jorge Guillén, pero luego lo han sido otros muchos americanos profesores en Estados Unidos como Fuentes, Lida, Margo Glanz, Isaías Lerner, que lo mismo han enseñado a Sor Juana que al Quijote. Como una anécdota emblemática podría sancionarlo el hecho de que cuando Carlos Fuentes recibió el Premio Cervantes se encontraba explicando el Quijote ese mismo curso en la Universidad de Brown. El Hispanismo ha sido un factor decisivo de cohesión cultural y literaria. Presidentes de esa Asociación Internacional de Hispanistas, creada en Oxford han sido Marcel Bataillon, Menéndez Pidal, Dámaso Alonso, Rafael Lapesa, Ana María Barrenechea., Franco Meregalli, Margit Frenk, Alan Deyermod, Agustín Redondo, Lía Schwartz, Aurora Egido y Jean-François Botrel.

Un sexto y último factor ha sido decisivo en la cohesión literaria del español como creación de unidad literaria: la actividad editorial. Lo primigenio y primordial de una cultura literaria la crea el libro que tienes en las manos, allá donde te encuentres. Y en el caso de la literatura escrita en español tan importante para América ha sido Seix Barral en Barcelona, creadora con el Premio Biblioteca Breve del conocido popularmente como boom de la narrativa americana, como para España lo ha sido el Fondo de Cultura Económica y las editoriales Losada y Sudamericana de Buenos Aires. Cualquier lector que haya vivido la dictadura de Franco conoce la experiencia de la trastienda del librero cómplice que te servía por vez primera títulos de Al- 
berti, de Ayala, de Max Aub, prohibidos en España o mutilados por la censura. Esos libros de españoles compartían catálogo editorial americano con los de Neruda, Lezama Lima u Octavio Paz. Esa realidad editorial que ha vinculado, con fuerza oscilante según las situaciones económicas de los países, las dos orillas de la realidad americana y española, continua pujante, pues hoy en día los principales grupos editoriales sirven de cauce indistinto a la literatura americana y española. Bolaño y Sergio Pitol, publicados por Anagrama, Elena Poniatowska o Fernado Vallejo por Alfaguara, etc., Manuel Puig por Seix Barral, Reinaldo Arenas por Tusquets, con sedes de esos grupos en cada uno de los principales países de América, de la misma forma que Emecé, Losada, Salamandra, son sellos de origen americano difusores de autores españoles.

\section{BASES TEÓRICAS DE UN CANON NARRATIVO HISPÁNICO}

Durante casi todo el siglo Xx el lugar de la interpretación operaba como una relación en el seno del circuito de comunicación literaria y el énfasis de cualquiera de los elementos de ese circuito (el autor, el texto el receptor) deparaba modificaciones de método, pero siempre respecto a un corpus de textos canónicos que no se discutía y que básicamente era adscrito a la continuidad del comentario que sobre los grandes clásicos establecía la comunidad interpretativa, quien fijó la noción misma de clásico en el seno de las tradiciones interpretativas.

La teoría literaria de hoy, en cambio, ya no se mueve siempre en el interior de tal circuito. Es más, lo que ha sometido a crisis es el circuito mismo, y no porque no se reconozca un emisor, un signo y un receptor, sino porque lo que ha tendido es a un desplazamiento del centro de su interés, que es ahora la relación entre el circuito semiótico y los sujetos que lo estudian. Por fortuna en el campo de los estudios españoles los seis factores que arriba he recorrido atemperan notablemente la dispersión que el corpus de estudio podría producir si el eje de vertebración fuese pivotado únicamente sobre la realidad nacional, la identidad sexual, racial o cualquiera otra.

La centralidad y recuperación actual de una cuestión vieja en los estudios literarios como la del canon es un signo muy sintomático. Diríamos que la emergencia de esa cuestión tiene que ver con esta modificación del estatuto de la teoría que hace prevalecer, previa a la interpretación de las obras, qué obras han de ser objeto de la interpretación y por qué esas y no otras. De ese 
modo el auténtico protagonista de la teoría actual no es ya cualquiera de los estratos de la interpretación, sino que ha devenido central lo que podríamos llamar utilizando el título de un ensayo de F. Kermode «el control institucional de la interpretación». Los sujetos de la lectura han cedido el paso, en el nuevo circuito, a los que podríamos llamar «sujetos de la Institución lectora», quiénes deciden esa lectura y sus modos, estrategias y principios selectivos. En este nuevo horizonte interpreto, junto a la centralidad obtenida por el debate en torno al canon, otra centralidad que le es contigua y que tiene que ver con la cuestión de las Humanidades: la cuestión pedagógica y en un sentido amplio la de la política cultural.

Obviamente los factores que arriba he resumido han logrado que el Hispanismo se haya visto menos afectado por estos cambios del canon que lo han sido otras culturas, como la de lengua inglesa, donde los estudios de Poscolonialismo han cobrado una pujanza enorme. El modelo que advino vinculado al concepto de identidad que vincula una lengua y una cultura, asentado en el programa que gobernó la primera Filología y que tenía en el Volgeist herderiano sus raíces más claras, ha querido proyectarse a menudo sobre las realidades literarias, pero en el caso de la escrita en español los factores enumerados han reducido las expectativas de ese modelo localista. El Hispanismo asienta su unidad en el modelo y la idea de una lengua única, el español o castellano, que respondía a una cultura asimismo unitaria, vertida por ese vehículo común que los escritores han convertido en tradición propia según arriba he venido mostrando.

Ese proyecto como fuerza centrífuga respecto a las identidades nacionales, choca sin embargo con la fuerte impronta que al canon literario y al consiguiente programa de estudios que le es anejo, porque todo canon es una paideia, un programa de estudios, un curriculum, que a menudo imponen las fuerzas centrípetas de las diferentes literaturas nacionales a las que se refería Octavio Paz: la argentina, la cubana, la peruana, mexicana, la española, etc. vinculadas a su vez a proyectos docentes subsidiarios de principios de identidad nacional.

Quizá fuese interesante, para dirimir el sentido de fuerzas centrífugas y centrípetas, no simplificar ante cuestiones tan espinosas y de tanto calado, a las que no me puedo referir aquí con detalle. Y para ello resultaría necesario volver a discutir las bases teóricas que la Literatura Comparada ha ido asentando, durante al menos el último siglo, sobre la dialéctica que Claudio Guillén convertía en programa: lo uno y lo diverso, lo nacional y lo transnacional, lo monolingüe y lo multilingüe. Por ejemplo, no deja nunca de cons- 
tituir un problema, pero ha nutrido la formulación misma de los corpus de textos desde el siglo XIX, el asentamiento de un canon sobre la idea de una identidad nacional vertebradora de la política cultural de cada país. La configuración del conjunto de la literatura italiana se hizo así en un determinado momento, según Tullio de Mauro mostró en la Italia del XIX, y no cabe duda de que la Literatura está siendo ahora vehículo portador y subsidiario a identidades culturales nacionales en este momento en el interior mismo del Estado español.

Sin embargo, el Hispanismo ha dejado de estar ya desde hace mucho tiempo, y por fortuna, nucleado en torno a la literatura peninsular española. Muchas naciones diferentes y espacios culturales diversos comparten su lengua y podrían también compartir un mismo canon de textos literarios. Así lo es en centros de estudio (Universidades e Instituto Cervantes) de todo el mundo.

El caso del Hispanismo no tendría que plantearse diferente al de otras literaturas, la mayoría, en las que no hay coincidencia entre Lengua y Estado, y tampoco entre lengua y territorio. ¿Forma parte Kafka de la literatura alemana?, ¿y los escritores austriacos? ¿A qué llamaríamos literatura suiza? Tendría que formar parte de ella Rousseau, pero no de la francesa? ¿Existiría un conjunto denominable como literatura árabe? No considero por tanto que el problema del Hispanismo, y de su corpus, es decir, que la pregunta acerca de si Borges pertenece a la literatura argentina, latinoamericana o hispánica sea diferente a la constitución misma del concepto de Literatura Comparada, como estudio de las dialécticas que en el seno de los estudios literarios acaecen y que no tienen una resolución unidireccional, y tampoco son resolubles por la vía de su confrontación, creando la falsa idea de que ser una de esas cosas implica no ser las otras. Sería absurdo decir que Borges no es argentino (lo es, incluso podría decirse que sobre todo porteño y bien se ve en rasgos de su literatura lírica), pero sería absurdo por ello decir que no pertenece al campo de la literatura hispánica, concebida como una unidad que Claudio Guillén (1998: 300) prefiere resumir en el sintagma «lengua portadora de literatura». El desafío es que Galdós, el propio Borges, García Márquez, Cela u Octavio Paz hayan logrado, como el Quijote en su día, ir más allá de esa lengua y ese vehículo para constituirse en unos de los referentes literarios de mayor calado universal, hasta lograr un lugar en ese canon no nacional, ni siquiera lingüístico, sino supralingüístico.

La lengua que llamamos «español», es portadora de literatura, y quizá sea menos importante marcar los adjetivos que tal literatura admita (de natura- 
leza nacional, sexual) que ver si puede ser proyectable en su dimensión universal, es decir, reconocibles por los otros, lo que pertenecen a otras comunidades culturales. Cuando digo universal no quiero significar categorías estéticas o principios absolutos ideados por el ideal romántico sobre una estética arquetípica. Me refiero a algo mucho más modesto, pero caracterizable empíricamente: la posibilidad de ser leídos, de ser comentados, de ser reconocidos como propios por habitantes de otras comunidades. Porque considero que el futuro del hispanismo no puede dirimirse en las guerrillas de sus fronteras interiores, cada una administradora de una cuota identitaria, que significaría a la larga un debilitamiento, no únicamente de sí mismo como comunidad académica, que sería lo de menos, sino en la capacidad que tengan los autores que escriben en esa lengua, para proyectarse hacia otredades, esto es, ganar espacios de reconocimiento por hablantes de otras lenguas y habitantes de otras culturas. Y por ende, de la responsabilidad que tienen esas comunidades académicas de facilitar tal proyección, lo que creo más fácil y estratégicamente más interesante si el sistema axiológico que define un corpus de textos depende menos de sus identidades centrípetas, sobre todo si ellas anulan aquella proyección exportadora de sus mejores obras.

El problema prioritario es establecer, por tanto, una modificación de la pregunta ¿existe un canon literario hispánico?, por esta otra: ¿cómo hacer llegar lo mejor de esa literatura, portada por esa lengua, provenga de la nación que provenga, tanto a quienes no pertenecen a esas comunidades nacionales o lingüísticas, como a los propios hablantes que forman parte de ellas y las desconocen? Obviamente he dicho «lo mejor de esa literatura» y soy consciente de que es un sintagma poco comprometido, que parece querer evitar el problema de las canonizaciones como modelos teóricos, axiológicos, ideológicos, etc., implicados en el proceso de toda selección.

No discuto y he escrito un libro para mostrarlo, que los principios de esa canonización han sido históricamente variables y lo serán en el futuro, y que su naturaleza es polisistémica. Pero querría decir que en un sentido de estrategia de política cultural es preciso dejar de lado ahora ese proceso de discusión interna, o mejor, arbitrarlo con una solución externa: dejemos que el canon literario hispánico no dependa tanto de nuestras propias identidades culturales, como de la negociación que seamos capaces de establecer tanto las comunidades académicas que a ello nos dedicamos como los propios autores y la industria cultural (editoriales, traducciones, etc.), para un reconocimiento que vaya más allá de nosotros mismos, y que dirima su destino por encima de las fronteras de nuestra lengua y de nuestra cultura. Considero 
prioritario advertir que son pocos todavía los autores hispánicos conocidos fuera del hispanismo, antes que discutir cuales deberían ser los enseñados en el interior de ese hispanismo. Y ello porque asumo que el hispanismo tiene un compromiso anterior y más fuerte con la Literatura que con el control institucional de su administración interna.

Por ello creo que el Hispanismo debe definir su corpus adquiriendo el compromiso ideológico de la Literatura como soporte de las Humanidades que ha de ser un compromiso crítico para con cada uno de los imaginarios culturales que se proponen fundamentos de la verdadera esencia de esa cultura, por el procedimiento y la responsabilidad que la teoría literaria tiene de mostrar, sine ira et estudio, esto es, de evidenciar empíricamente, la naturaleza convencional e histórica de cada uno de los procesos de su afirmación. De modo que la cultura y la literatura sea capaz de huir de los reduccionismos a que quiere verse sometida por cada uno de los parapetos ideológicos que han nutrido las diferentes interpretaciones de los textos, incluidos los nuevos episodios de moralismo excluyente que las nociones de lo políticamente correcto vienen imprimiendo a los llamados «estudios culturales» algunas de cuyas formulaciones peligrosamente se deslizan hoy por una pendiente de «identidad» que sobrepasa ya las primitivas concesiones estratégicas al pensamiento fundado en el nervio revolucionario de lo antisistémico y periférico, para edificar nuevos centros canonizadores con igual fuerza excluyente e igual comportamiento acrítico con el principio de «identidad cultural» que las que habían originado sus propias reacciones.

No se trata, en un hispanismo moderno, de una erradicación simplista de las diferencias para la administración de cánones, en una suerte de globalización trascendental a ellas, sino de admitir que la literatura misma, pueda actuar como espacio de complejidad hermenéutica donde las diferencias son no sólo reconocidas y comprendidas sino asimismo intercambiadas y discutidas. Un hispanismo plural, por tanto, crítico y consciente de su responsabilidad histórica: la de llevar la literatura escrita en español más allá de sí misma.

\section{REFERENCIAS BIBLIOGRÁFICAS}

GUILLÉN, C. (1998). Múltiples moradas: ensayo de literatura comparada. Barcelona: Tusquets. 
MÚJICA LÁINEZ, M. (1950). Misteriosa Buenos Aires. Buenos Aires: Editorial Sudamericana, 1999.

PAZ, O. (1991). «Unidad, modernidad, tradición». En Obras Completas. Barcelona: Círculo de Lectores, vol. III.

POZUELO YVANCOS, J. M. ${ }^{\mathrm{a}}$ y ARADRA SÁNCHEZ, R. M. ${ }^{\mathrm{a}}$ (2000). Teoría del canon y literatura española. Madrid: Cátedra. 